\section{Acute renal failure in four HIV- infected patients: Potential association with tenofovir and nonsteroidal anti-inflammatory drugs}

\section{To the Editor:}

Although infrequent, tenofovir has been associated with chronic renal dysfunction and Fanconi syndrome, usually in the setting of multifactorial causes for renal dysfunction or in patients with underlying renal disease. We report four cases of acute renal failure in patients with other factors for renal failure, in which tenofovir in combination with nonsteroidal anti-inflammatory drugs (NSAIDs) may be a contributing factor.

A 48-year-old man with hepatitis $\mathrm{C}$ cirrhosis, ChildPugh B score of 8 out of 15 and portal hypertension had mild, but stable, renal insufficiency (usual creatinine level $115 \mu \mathrm{mol} / \mathrm{L}$ and creatinine clearance $49 \mathrm{~mL} / \mathrm{min}$ ). He was taking an antiretroviral regimen of lopinavir-ritonavir, didanosine (adjusted dose of $250 \mathrm{mg}$ ) and tenofovir for 10 months. His CD4 count was 180 cells $/ \mathrm{mL}$ and his viral load (VL) was less than 50 copies $/ \mathrm{mL}$. He was abstinent from drugs, but continued to drink alcohol on rare occasions. The patient was on furosemide and spironolactone for the management of ascites. The rest of his medication included co-trimoxazole, hydromorphone, quinine, omeprazole and dimenhydrinate. The patient received a prescription of naproxen, $375 \mathrm{mg}$ three times a day, for backache. Five days later, he was admitted to hospital with a deteriorated general condition. His creatinine level was $467 \mu \mathrm{mol} / \mathrm{L}$, urea concentration was $32.6 \mathrm{mmol} / \mathrm{L}$, phosphorus concentration was $1.97 \mathrm{mmol} / \mathrm{L}$ and potassium concentration was $14.1 \mathrm{mmol} / \mathrm{L}$. Hydration and potassium chelators were given, and all his medications withheld. A diagnosis of acute tubular necrosis secondary to naproxen was made. His renal status was considered irreversible, and the patient died two days after admission.

The second case was a 63-year-old man suffering from hepatitis B cirrhosis with splenomegaly, esophagitis, chronic bronchitis, personality disorder and HIV for 15 years. His HIV disease was stable on an antiretroviral regimen of tenofovir, lamivudine and lopinavir-ritonavir. His CD4 count was 240 cells/mL and his VL was less than 50 copies $/ \mathrm{mL}$. He was using cocaine but not alcohol. The patient also took olanzapine, paroxetine and bupropion. He had recently started taking naproxen $500 \mathrm{mg}$ twice daily. The patient was admitted to the emergency room for hemiparesis, hematemesis and fever. Rhabdomyolysis and acute renal failure secondary to cocaine intoxication was diagnosed. His baseline creatinine clearance was $73 \mathrm{~mL} / \mathrm{min}$ (creatinine level $105 \mu \mathrm{mol} / \mathrm{L}$ ). On admission, his creatinine level was $272 \mu \mathrm{mol} / \mathrm{L}$, urea concentration was $10.4 \mathrm{mmol} / \mathrm{L}$ and creatine kinase (CK) level was $222 \mathrm{U} / \mathrm{L}$. He was treated with rehydration only. The next day his CK level was $9300 \mathrm{U} / \mathrm{L}$. While hospitalized, naproxen was stopped, but the patient continued his tenofovir-based regimen without any change in dosage. He was discharged from hospital three days later with a creatinine level of $97 \mu \mathrm{mol} / \mathrm{L}$ and a CK level of $977 \mathrm{U} / \mathrm{L}$.

The third patient was a 53-year-old man suffering from osteoporosis, cardiovascular disease, chronic lumbar degenerative disc disease, anemia, hepatic steatosis and perone disease. His antiretroviral regimen consisted of tenofovir, didanosine (adjusted dose of $250 \mathrm{mg}$ ), atazanavir and ritonavir, prescribed for over one year. His CD4 count was 60 cells/mL and his VL was less than 50 copies $/ \mathrm{mL}$. He consumed alcohol regularly, but took no other drugs. The patient also took trimethoprimsulfamethoxazole, temazepam, ranitidine, lorazepam, sertraline, propranolol and acetylsalicylic acid. Since the introduction of tenofovir, he had been screened regularly for nephrotoxicity. His creatinine level was stable at $95 \mu \mathrm{mol} / \mathrm{L}$ (creatinine clearance $75 \mathrm{~mL} / \mathrm{min}$ ), phophorus concentration was $0.86 \mathrm{mmol} / \mathrm{L}$ and urinary glucose concentration was $0 \mathrm{mmol} / \mathrm{L}$. He received a prescription of indomethacin suppositories, $100 \mathrm{mg}$ twice daily, for backache. One week later, he was admitted to hospital for deteriorated general condition. On admission, his creatinine level was $1454 \mu \mathrm{mol} / \mathrm{L}$, urea concentration was $46.3 \mathrm{mmol} / \mathrm{L}$, potassium concentration was $5.5 \mathrm{mmol} / \mathrm{L}$, phosphorus concentration was $1.68 \mathrm{mmol} / \mathrm{L}$, urinary glucose concentration was $3 \mathrm{mmol} / \mathrm{L}$ and proteinuria level was $5 \mathrm{~g} / \mathrm{L}$. All medications were stopped. Over the next few weeks, he required dialysis two or three times a week. Between each dialysis, his creatinine level increased to $700 \mu \mathrm{mol} / \mathrm{L}$. A diagnosis of irreversible acute tubular necrosis secondary to NSAID was made. The patient expressed a wish to stop dialysis and discontinue antiretrovirals. He continued his follow-up on an outpatient basis and died 12 months later.

The fourth case was a 46-year-old man who had HIV for 15 years, chronic diarrhea for three years, diabetes, hypertriglyceridemia, hepatic steatosis, pancytopenia, arthrosis, epilepsy, leukocytoclastic vasculitis and herpes simplex virus. His HIV therapy consisted of saquinavir hard gel, ritonavir, didanosine (unadjusted dose of $400 \mathrm{mg}$ ), tenofovir and lamivudine. Before this salvage regimen, his VL was 171,401 copies $/ \mathrm{mL}$, his CD4 count was 10 cells $/ \mathrm{mL}$ and his baseline creatinine level was $84 \mu \mathrm{mol} / \mathrm{L}$ (creatinine clearance $87 \mathrm{~mL} / \mathrm{min}$ ). He did not use drugs, but did drink alcohol and smoke tobacco. Other medications included atovaquone, glyburide, niacin, rosuvastatin, probenecid, fluconazole and azithromycin. He was admitted to hospital for one-week long diarrhea (four times a day) and vomiting (three times a day), but

Continued on page 76 


\section{LETTER TO THE EDITOR}

Continued from page 75

could still eat and drink. On admission, his creatinine level was $346 \mu \mathrm{mol} / \mathrm{L}$ and tenofovir was stopped. A diagnosis of acute renal failure secondary to dehydration was made, in addition to chronic renal failure secondary to tenofovir. His bicarbonate and phosphorus levels were normal, and he had no proteinuria or glucosuria. Fanconi, nephritic or nephrotic syndromes were not found. Renal function improved with rehydration, and the patient was discharged (creatinine level $168 \mu \mathrm{mol} / \mathrm{L}$ ) with reference to his physician to choose other antiretrovirals.

Our patients had acute renal failure with elevated creatinine levels, and elevated urea and potassium concentrations, without hypophosphoremia or glucosuria. Each of our four cases had multiple risk factors for renal failure. In the first case, the use of diuretics, the baseline renal status, the hepatic condition (with possible hepatorenal syndrome) and the use of tenofovir might have predisposed the patient to NSAID-induced renal failure. In the second and third cases, NSAIDs were probably the triggering agent as well, but the patients had fewer risk factors for renal insufficiency. In the fourth case, diabetes and the progressively increasing creatinine secondary to tenofovir might have been the risk factors for acute renal failure caused by dehydration. Also, three of the four patients took didanosine in combination with tenofovir, which may have predisposed them to cellular toxicities.

Four patients treated with tenofovir developed acute renal failure without Fanconi syndrome. The cumulative use of diuretics, didanosine, NSAIDs, tenofovir and other underlying diseases altering kidney function, such as diabetes or liver cirrhosis, may have played a role in these cases. Larger cohort studies are required to better define the nature and risk of acute renal failure in HIV-positive patients who are treated with tenofovir and NSAIDs. Nonetheless, based on this case series, we feel it prudent to recommend that the combination of tenofovir and NSAIDs be used with extreme caution, especially in HIVinfected patients who have other risk factors for renal dysfunction.

NOTE: Two of these cases have been previously published in the Canadian Adverse Effects Bulletin, April 2006.

Suzanne Marcotte BPharm MSc Annie Talbot MD

Benoit Trottier MD

Unité hospitalière de recherche et d'enseignement sur le SIDA du Centre hospitalier de l'université de Montréal,

Montreal, Quebec

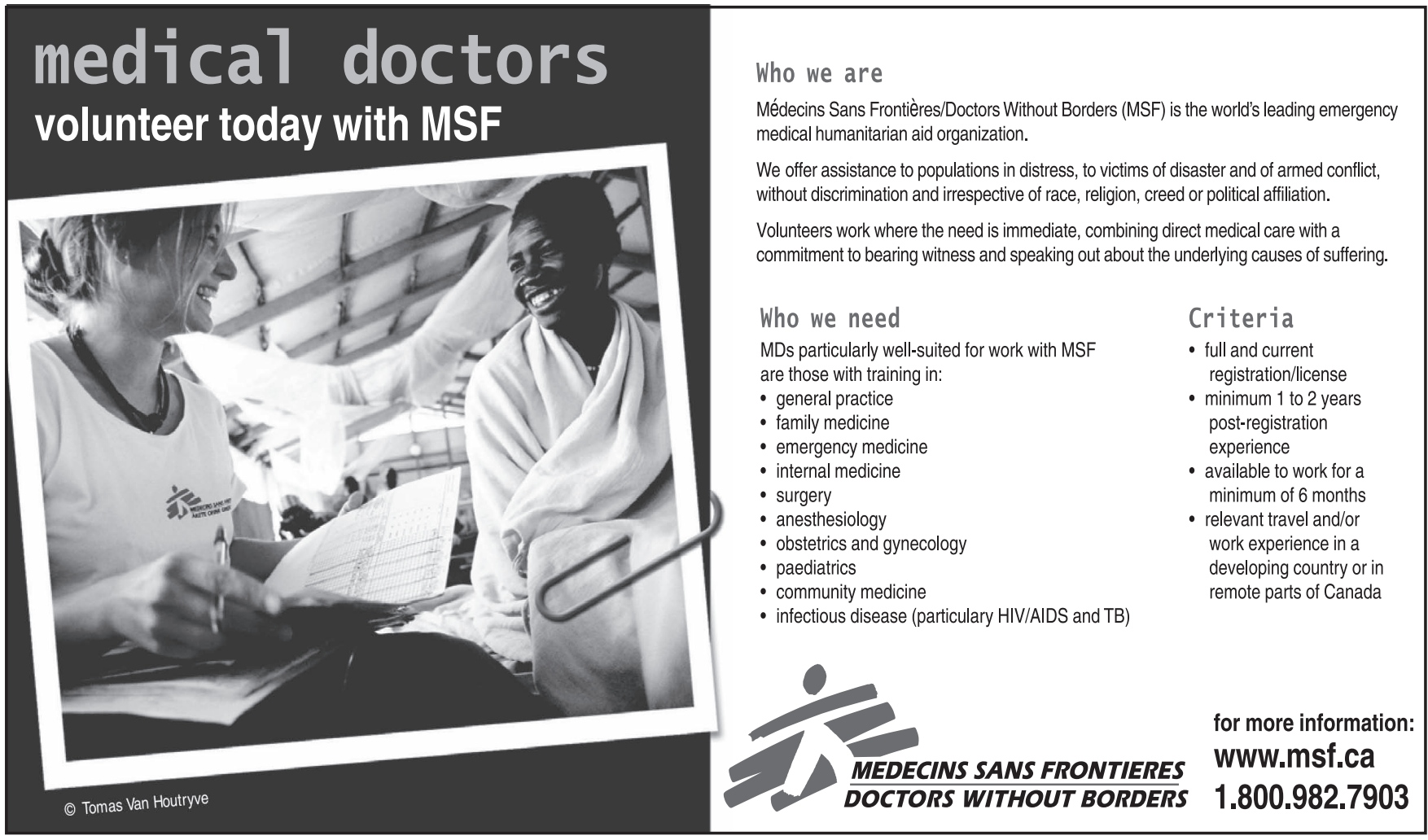




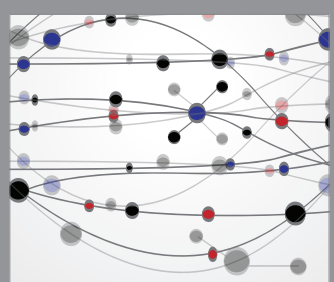

The Scientific World Journal
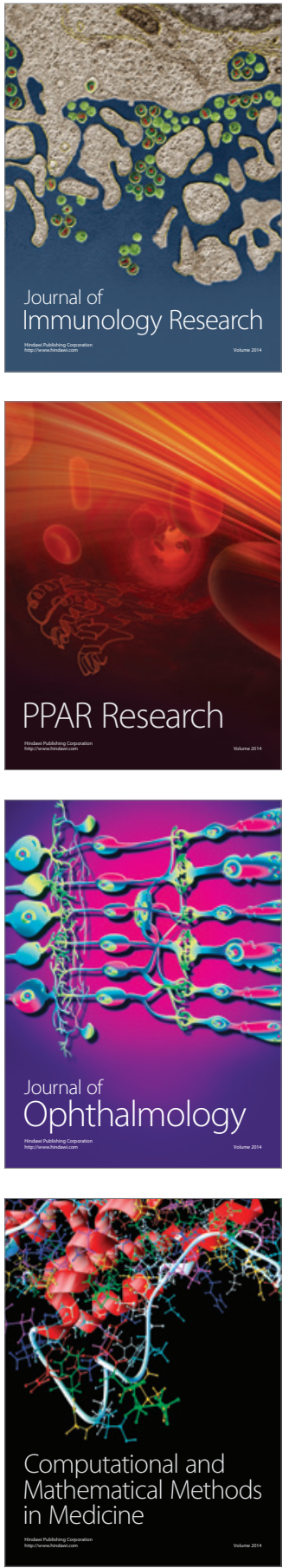

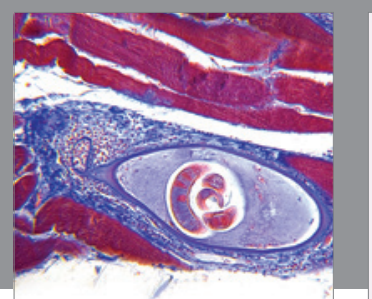

Gastroenterology Research and Practice

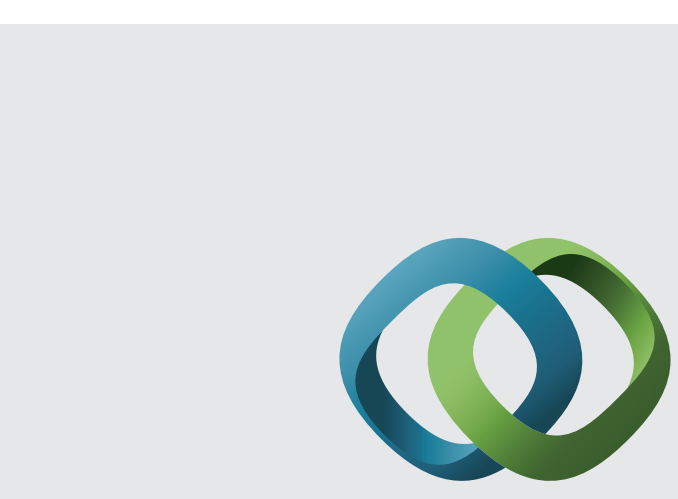

\section{Hindawi}

Submit your manuscripts at

http://www.hindawi.com
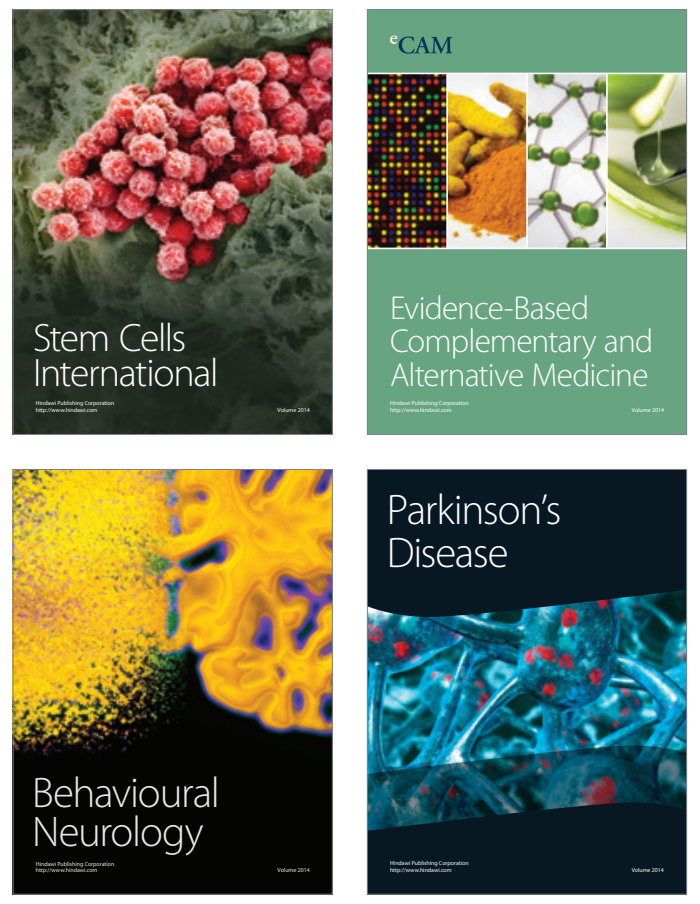
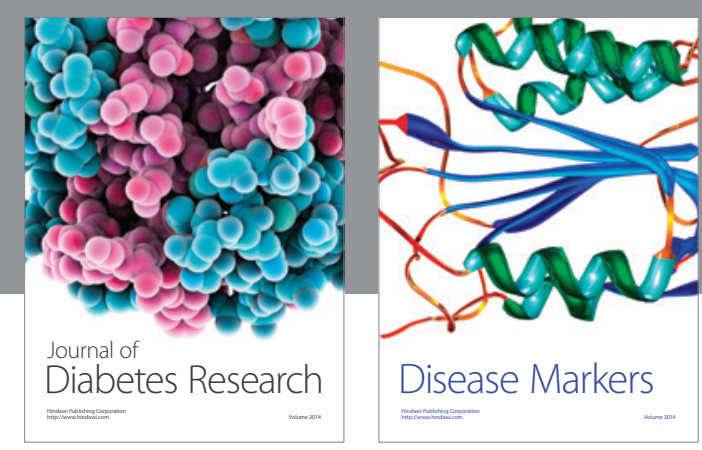

Disease Markers
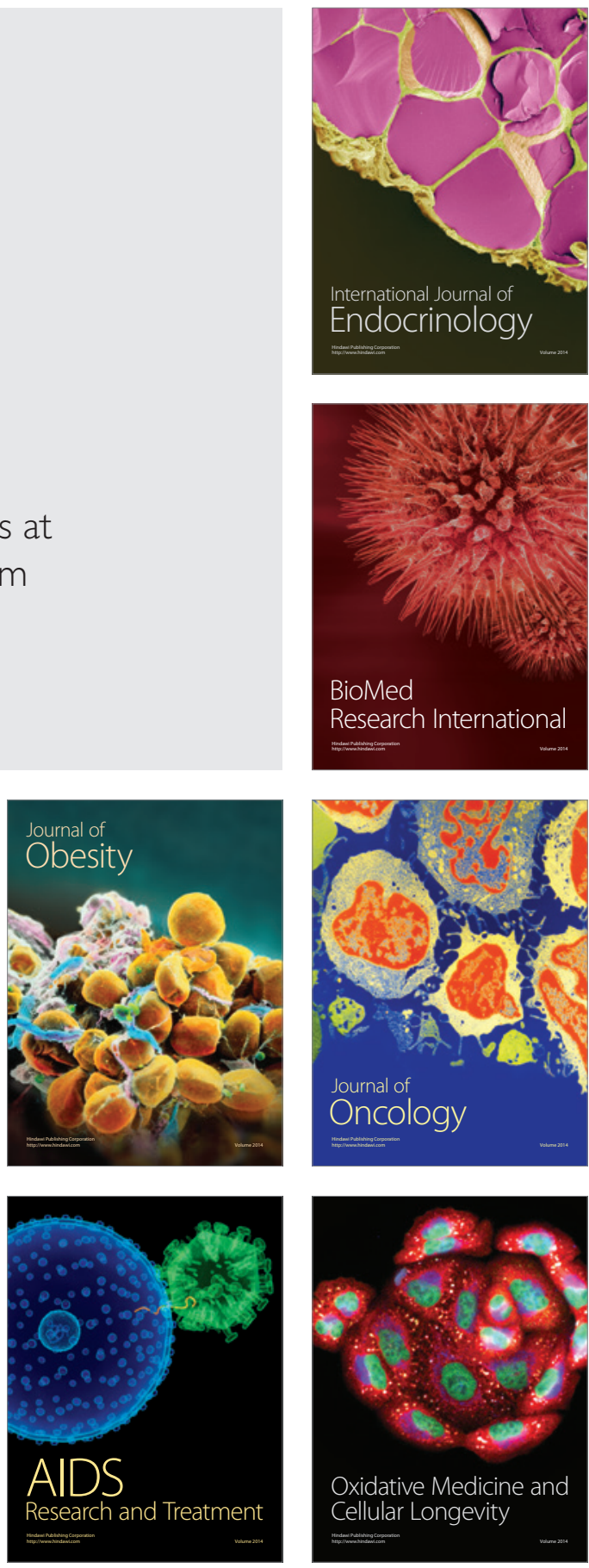